\section{Endoscopy-assisted percutaneous anterior gastropexy for gastric volvulus: a minimally invasive technique using a special instrument}

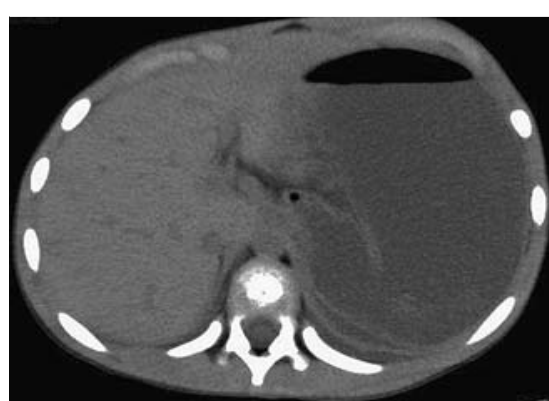

Fig. 1 Enhanced abdominal computed tomography (CT) scan in a 5-year-old boy with sudden onset mild abdominal pain and vomiting showing gastric dilatation.
A 5-year-old boy, who had had repeated episodes of vomiting, developed sudden onset mild abdominal pain and vomiting. An enhanced computed tomography (CT) scan showed marked distension of the stomach ( Fig. 1) and a barium meal revealed a suspected mesenterioaxial gastric volvulus ( $\bullet$ Fig. 2 a). No evidence of a hiatal hernia or mucosal ischemic change was observed on esophagogastroduodenoscopy. Therefore, the abnormal rotation was reduced using an endoscope to the normal anatomical position, which was

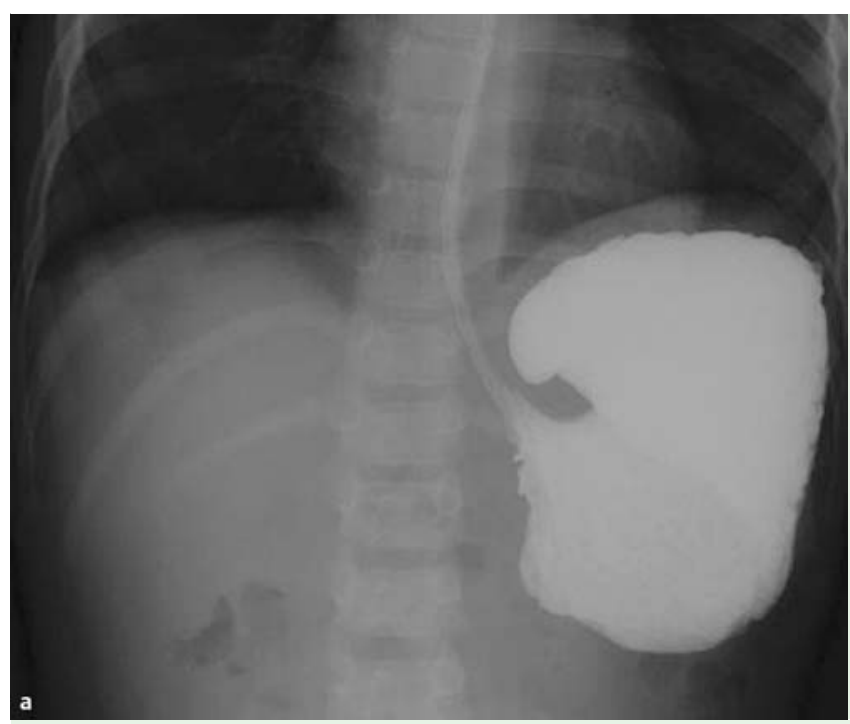

Fig. 2 Barium images showing: a a mesenterioaxial gastric volvulus (contrast administered through a nasogastric catheter); $\mathbf{b}$ the stomach back in its normal anatomical position following endoscopic reduction of the volvulus.

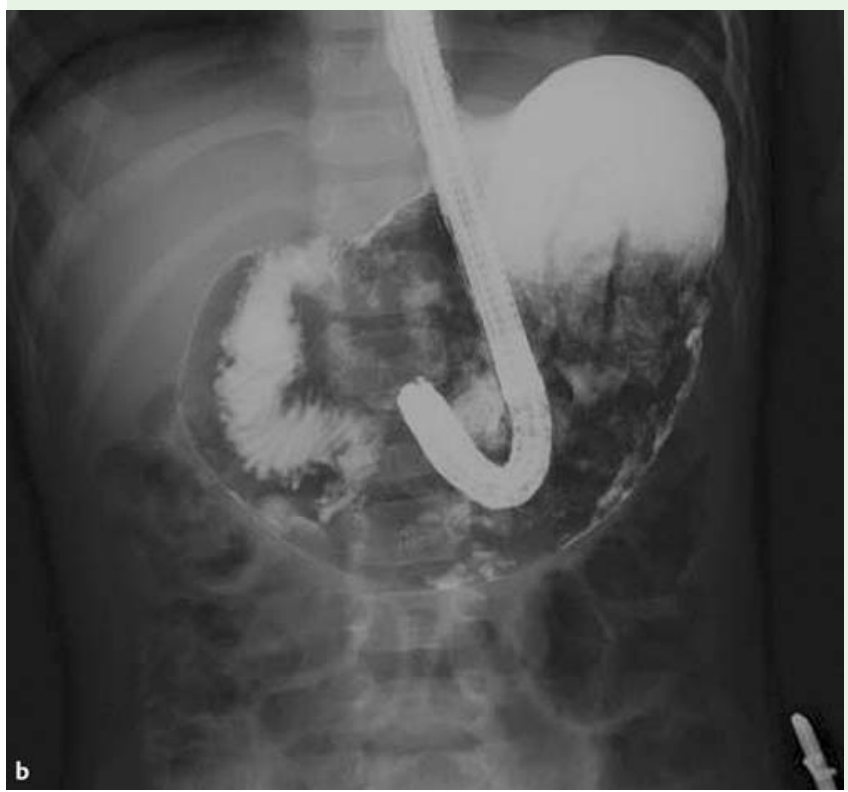

confirmed radiologically ( Fig. 2 b). The post-therapeutic course was uneventful. The patient underwent endoscopy-assisted percutaneous gastropexy 2 months after this episode. This was performed using the gastropexy device that is included in the Kangaroo Seldinger percutaneous endoscopic gastrostomy (PEG) kit (Nippon Sherwood Medical Industries Ltd., Tokyo, Japan; Fig. 3). This device is normally used for gastropexy during PEG insertion, when it is simply fixed in position through the skin, peritoneum, and anterior stomach wall from the percutaneous site by nonabsorbable sutures. The fixation for the gastric volvulus was located under endoscopic observation at two points within the stomach: the middle part of the gastric body and the antrum ( Fig.4). The total time under intravenous sedation for the endoscopic operation was 10 minutes. A mild skin infection was observed postoperatively, but healed immediately with antibiotics. During longer term follow-up, he has remained well and symptom free.

Gastric volvulus is being recognized with increasing frequency because of recent improvements in diagnostic instruments $[1,2]$. Generally gastropexy by an open or laparoscopic procedure is performed in cases without coexisting problems such as hiatal hernia or organ malformations $[3,4]$. In the present case an endoscopyassisted percutaneous gastropexy was performed at the middle part of the gastric body and the antrum using a special instrument. Although this endoscopy-assisted gastropexy, unlike conventional methods, is able to fix only the anterior wall of the stomach, mesenterioaxial gastric volvulus without comorbidity is a good indication because fixation of the antrum is mandatory.

In conclusion, we have demonstrated the first endoscopy-assisted percutaneous gastropexy for chronic organoaxial gastric volvulus. This procedure is technically feasible, effective, and safe; however, the explanation for the gastric volvulus must be evaluated first.

Endoscopy_UCTN_Code_TTT_1AO_2AN

Competing interests: None 


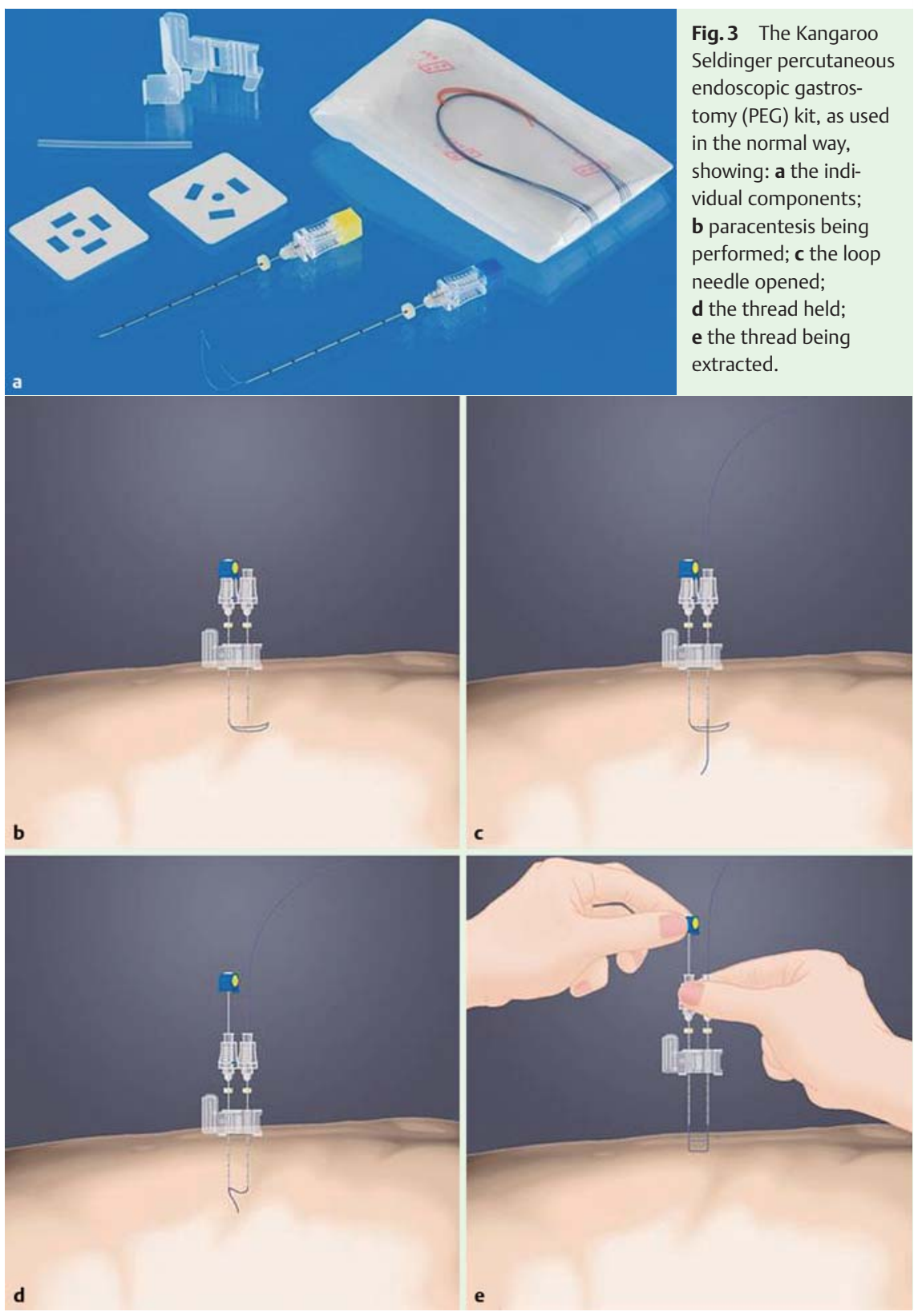

M. Kawai ${ }^{1}$, M. Hiramatsu ${ }^{1}$, S.-W. Lee ${ }^{1}$,

T. Tokuhara ${ }^{1}$, Y. Fujita ${ }^{1}$, E. Nomura',

K. Inoue ${ }^{2}$, A. Yoden ${ }^{2}$, H. Tamai²,

K. Uchiyama'

${ }^{1}$ Department of General and Gastroenterological Surgery, Osaka Medical College, Osaka, Japan

2 Department of Pediatrics, Osaka Medical College, Osaka, Japan

\section{References}

1 Samuel M, Burge DM, Griffiths DM. Gastric volvulus and associated gastroesophageal reflux. Arch Dis Child 1995; 73: 462 - 464

2 Wasselle JA, Norman J. Acute gastric volvulus: pathogenesis, diagnosis, and treatment. Am J Gastroenterol 1993; 88: 1780-1784

3 Palanivelu C, Rangarajan $M$, Shetty AR. Laparoscopic suture gastropexy for gastric volvulus: a report of 14 cases. Surg Endosc 2007; 21: $863-866$

$4 \mathrm{Al}$-Salem $\mathrm{AH}$. Acute and chronic gastric volvulus in infants and children: who should be treated surgically? Pediatr Surg Int 2007; 23: $1095-1099$

\section{Bibliography}

Dol http://dx.doi.org/

10.1055/s-0032-1326461

Endoscopy 2013; 45: E151-E152

(c) Georg Thieme Verlag KG

Stuttgart · New York

ISSN 0013-726X

\section{Corresponding author}

\section{Kawai, MD}

Department of General and Gastroenterological Surgery

Osaka Medical College

2-7 Daigaku-machi, Takatsuki-city

Osaka 569-8686

Japan

Fax: +81-72-6852057

sur080@poh.osaka-med.ac.jp

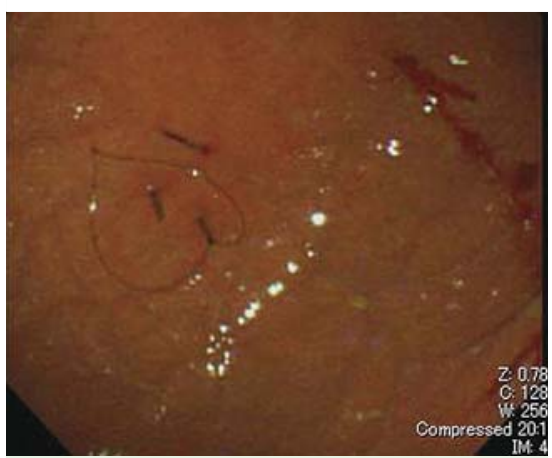

Fig. 4 Endoscopic view showing the fixation in our case at two points within the stomach: the middle part of the gastric body and the antrum. 